\title{
Atrial natriuretic factor: the heart as an endocrine organ
}

It has been known for some years that secretory granules exist within atrial myocytes, that the density of these granules is altered by changes in fluid balance, and that distention of the atria induces diuresis and natriuresis, and suppresses release of renin, aldosterone, and vasopressin. With the discovery that extracts of cardiac atria contain a potent natriuretic factor (ANF), that the granules are the storage site for ANF, and that atrial distention provokes ANF release, it became clear that the atria have both afferent and efferent functions in circulatory homoeostasis. ${ }^{1}$ However, ANF is not de Wardener's 'third factor'.

ANF is a 28 amino acid peptide which is released after cleavage of a 126 amino acid storage precursor and has a half life of 2-3 minutes. The only definite sources of circulating ANF are the cardiac atria but ANF also appears to be present in lung, brain, and fetal cardiac ventricles.

ANF release is stimulated by atrial distention, increase in intravascular volume, increased atrial pressure, and dietary sodium loading. ${ }^{2}$ ANF release is also provoked by infusion of $\alpha$ adrenergic agonists, angiotensin II, and antidiuretic hormone. ${ }^{1}$ ANF acts via a 'second messenger', cyclic guanosine monophosphate.

\section{Actions of atrial natriuretic factor}

Caution is needed here because of the unphysiological doses of ANF used in many studies. Studies in animals and adult man show that ANF has endocrine, renal, and vasomotor actions. Not only does ANF directly inhibit release of renin, aldosterone, and antidiuretic hormone, ${ }^{34}$ but ANF also antagonises the target organ effects of angiotensin II and antidiuretic hormone. ${ }^{1}$ As a result of these actions and of a paradoxical constrictive effect on the glomerular efferent arteriole, ANF causes an increase in glomerular filtration rate, and a diuresis and natriuresis. These actions suggest that antagonism of the renin-angiotensin-aldosterone system may represent a major function of ANF.

ANF administration is associated with a variable decrease in systemic blood pressure and a transient increase in regional blood flow to kidneys, lung, and myocardium. ${ }^{1}$ ANF attenuates the pulmonary vasoconstriction induced by hypoxia $^{5}$ and may act as a bronchodilator. ${ }^{6}$ ANF also induces a shift of fluid from the vascular to the extravascular space, possibly by increasing capillary leakiness. ${ }^{7}$ Finally, ANF may function as a neurotransmitter peptide and has direct effects on the central nervous system such as the inhibition of thirst. ${ }^{14}$

\section{Atrial natriuretic factor in the fetus}

Fetal umbilical arterial ANF concentrations are not correlated with maternal concentrations and are the same or slightly higher. ${ }^{8}$ Umbilical artery ANF concentration is significantly greater than umbilical vein concentration, suggesting that the placenta consumes or takes up ANF. The human placenta has ANF binding sites and there is some evidence of a placental barrier to ANF transfer. ${ }^{10}$

ANF concentrations increased appropriately in response to hypervolaemia, ${ }^{11}$ and decreased with haemorrhage (R A Brace, C Y Cheung, personal communication) in the sheep fetus. In this model, fetal ANF also increased in response to hypoxia, ${ }^{11}$ which may be significant in view of the pulmonary vasodilator actions of $A N F,{ }^{5}$ and fetal urine production increased in response to ANF. ANF concentrations were significantly raised in human fetuses undergoing cordocentesis for Rhesus isoimmunisation at 28 weeks' gestation, and the ANF concentrations increase further after intrauterine transfusion. ${ }^{8}$ This suggests that in the human fetus, at least by the third trimester, ANF concentrations increase with pathological or iatrogenic volume expansion. Fetal ANF may also increase umbilical blood flow, ${ }^{12}$ and a decreased density of ANF receptors has been reported in placentas from pregnancies complicated by intrauterine growth retardation.

\section{Atrial natriuretic factor in the newborn}

The changes in right atrial pressure, glomerular filtration rate, and fluid balance that occur in the immediate postnatal period in normal term infants would suggest that ANF may have a physiological role. ${ }^{13}$ ANF may also have a role in respiratory illness as a diuresis occurs during the recovery phase of respiratory distress syndrome, and failure of such a diuresis may be predictive of the later development of bronchopulmonary dysplasia.

Normal values for ANF concentrations show no age variation beyond the neonatal period. ${ }^{914}$ ANF concentrations are only slightly raised in cord blood compared with later life, ${ }^{15}$ but they increase dramatically over the first few days in normal term infants and remain high throughout the first week of postnatal life. ${ }^{914}$ Although this increase in plasma ANF mirrors the course of postnatal negative salt and water balance, ${ }^{13}$ there was no correlation between ANF concentrations and urine sodium excretion. ${ }^{15}$ Dietary salt loading of premature infants increases plasma ANF, ${ }^{16}$ and this perhaps explains why previous attempts at manipulating intake to prevent early postnatal hyponatraemia have failed.

In premature infants with respiratory distress syndrome, we have also observed a significant increase in ANF concentrations over the first few days of life ( $T$ Stephenson, F Broughton Pipkin, D Hetmanski, unpublished observations), and they are higher the more severe the respiratory distress ${ }^{17}$ and highest during the diuretic phase of the illness. ${ }^{18}$ The ANF concentrations observed in these premature infants are much higher than in healthy term infants and yet, despite this, renin concentrations are also very high in the early postnatal period. ${ }^{19}$ Persistence of high ANF and antidiuretic hormone concentrations beyond early postnatal life may be associated with bronchopulmonary dysplasia. ${ }^{20}$

Atrial natriuretic factor and cardiac disease in childhood In the premature infant, plasma ANF concentrations were raised in the presence of a patent ductus arteriosus ${ }^{21}$ and fell with surgical ligation. In neonates with transposition of the great vessels, plasma ANF concentration correlated with left atrial pressure and ANF fell after septostomy. ${ }^{22}$ In older children with heart failure, the concentrations were above the normal range ${ }^{1423}$ and fell after treatment. ${ }^{23}$ These authors suggested that ANF may be useful in the treatment of heart failure, as it may reduce both preload and afterload. 
In children with septal defects, ANF concentrations were also increased and correlated with shunt size. ${ }^{23}$ Davis et al found that atrial pacing in children increased plasma ANF concentrations, although atrial pressure was unchanged, the increase in ANF being related to the increase in rate. ${ }^{24}$ This is consistent with the diuresis which follows episodes of supraventricular tachycardia.

Atrial natriuretic factor and renal disease in childhood Normotensive children on maintenance haemodialysis have predialysis ANF concentrations which are significantly higher than ANF concentrations in normal children or children with advanced renal failure but no volume expansion. ${ }^{25}$ Plasma concentrations fell significantly during haemodialysis and the magnitude of this fall was directly related to the fall in body weight during dialysis. ${ }^{24}$ In animal models, prompt 'rescue' infusion of ANF after either noradrenaline or gentamicin induced renal failure significantly improved glomerular filtration rate, urine volume, and sodium excretion. ${ }^{2}$

\section{Hypertension}

In essential hypertension, ANF concentrations were normal in childhood but raised by adolescence. ${ }^{26}$ Whereas plasma ANF correlated with fractional and 24 hour urinary excretion of sodium in matched normotensive controls, no correlation was found in the smaller number of hypertensives. An impaired ANF response to high dietary salt intake has been reported in the offspring of hypertensive parents. ${ }^{27}$ These two studies suggest that in childhood essential hypertension, the contribution of ANF to sodium balance may be abnormal and this may help to clarify the complex pathogenesis and familial clustering of this condition.

\section{Metabolic disorders}

It has been suggested that Bartter's syndrome may be a 'syndrome of inappropriate ANF secretion' (as these patients are volume contracted), ${ }^{28}$ but the raised ANF concentration may also be secondary. Gordon's syndrome may result from end organ insensitivity to ANF. ${ }^{28}$ ANF concentrations are increased in adults with endogenous or exogenous glucocorticoid excess ${ }^{2}$ and primary hyperaldosteronism ${ }^{28}$ and ANF falls to normal with treatment.

\section{Summary}

The growth in understanding about ANF over the last 10 years reflects the pace of modern biological research. Within three years of the initial report that atrial extract contained a natriuretic factor, human ANF was purified, sequenced, and cloned. Atrial dimension is the major determinant of ANF release, ANF has natriuretic and vasodilator effects, and ANF has a definite role in response to an acute increase in intravascular volume. It is not yet clear how important ANF is in the regulation of sodium and water balance and blood pressure under steady state, physiological conditions.

Most of our understanding is derived from experimental studies in animal models or from observational studies in adult man. The production of ANF by biotechnology allows interventional studies, however, and further advances may be made if specific antagonists of ANF can be developed. ANF may have therapeutic potential in the treatment of heart failure, respiratory distress syndrome, acute renal failure, oedema and ascites, systemic and pulmonary hypertension, and asthma. ANF anatgonists might prevent hyponatraemia of prematurity and alleviate Bartter's syndrome. ANF is not nephrotoxic and is without many of the side effects of current diuretics and vasodilators but its use is currently limited by the very short half life and the need for intravascular administration.

T J STEPHENSON Department of Child Health F BROUGHTON PIPKIN Department of Obstetrics

Queen's Medical Centre,

Nottingham NG7 2UH

1 Atlas SA, Cody RJ, Carmargo MJF, Pecker MS, Volpe M, Laragh JH. Atrial natriuretic factor and its role in circulatory physiology. In: Edwards CRW, Lincoln DW, eds. Recent advances in endocrinology and metabolism. London: Churchill Livingstone, 1989:281-313.

2 Davis AL. Atrial natriuretic factor. Adv Pediatr 1989;36:137-50.

3 Atlas SA, Maack T. Effects of atrial natriuretic peptide on the kidney and the renin-angiotensin-aldosterone system. Endocrinology and Metabolism Clinics of North America 1987;16:107-43.

4 Samson WK. Atrial natriuretic factor and the central nervous system. Endocrinology and Metabolism Clinics of North America 1987;16:145-61.

5 Adnot S, Chabrier PE, Brun-Buisson C, Viossat I, Braquet P. Atrial natriuretic factor attenuates the pulmonary pressor response to hypoxia. $\mathcal{F} A p p l$ tic factor attenuates the pulf
Physiol 1988;65:1975-83.

6 Hulks G, Jardine A, Connell JMC, Thomson NC. Bronchodilator effect of atrial natriuretic peptide in asthma. Br Med $\mathcal{F}$ 1989;299:1081-2.

7 Huxley VH, Tucker VL, Verburg KM, Freeman RH. Increased capillary hydraulic conductivity induced by atrial natriuretic peptide. Circ Res 1987; 60:304-7.

8 Kingdom JCP, Jardine AG, Doyle J, Connell JMC, Gilmore DH, Whittle MJ. Atrial natriuretic peptide in the fetus. Br Med f 1989;298:1221-2.

9 Kikuchi K, Shiomi M, Horie K, et al. Plasma atrial natriuretic peptide concentration in healthy children from birth to adolescence. Acta Paediatr Scand 1988;77:380-4.

10 Mulay S, Varma DR. Placental barrier to atrial natriuretic peptide in rats. Can f Physiol Pharmacol 1989;67:1-4.

11 Cheung CY, Brace RA. Fetal hypoxia elevates plasma natriuretic factor concentration. Am f Obstet Gynecol 1988;159:1263-8.

12 Kingdom JCP, Jardine AG, Connell JMC, Templeton A, Whittle MJ. Atrial natriuretic peptide opposes the vasoconstrictor effect of angiotensin II in the placenta. Placenta 1989;10:481.

13 Stephenson TJ, Rutter N. Neonatal fluid balance. In: Campbell A, McIntosh $\mathrm{N}$, eds. Forfar and Ameil's textbook of paediatrics. Edinburgh: Churchill Livingstone (in press)

14 Weil J, Bidlingmaier F, Dohlmann C, Kuhnle U, Strom T, Lang RE. Comparison of plasma attrial natriuretic peptide levels in healthy children from parison of plasma attrial natriuretic peptide levels in healthy children from
birth to adolescence and in children with cardiac disease. Pediatr Res 1986; 20:1328-31.

15 Ito $\mathrm{Y}$, Matsumoto T, Ohbu K, et al. Concentration of human atrial natriuretic peptide in cord blood and plasma of the newborn. Acta Paediatr Scand 1988;77:76-8.

16 Tulassay T, Rascher W, Seyberth HW, Lang RE, Toth M, Sulyok E. Role of atrial natriuretic peptide in sodium homeostasis in premature infants. f Pediatr 1986;109:1023-7.

17 Shaffer SG, Geer PG, Goetz KL. Elevated atrial natriuretic factor in neonate with respiratory distress syndrome. $\mathcal{f}$ Pediatr 1986;109:1028-33.

18 Kojima T, Hirata Y, Fukuda Y, Iwase S, Koyabashi Y. Plasma atrial natriuretic peptide and spontaneous diuresis in sick neonates. Arch Dis Child 1987, 62:667-70.

19 Broughton Pipkin F, Stephenson TJ. Plasma renin and renin substrate concentrations in the very premature human baby. Early Hum Dev 1989;19:71.

20 Kojima T, Fukuda Y, Hirata Y, Matsuzaki S, Kobayashi Y. Changes in vasopressin, atrial natriuretic factor, and water homeostasis in the early vasopressin, atrial natriuretic factor, and water homeostasis in the
stages of bronchopulmonary dysplasia. Pediat Res 1990;27:260-3.

21 Rascher W, Seyberth HW. Atrial natriuretic peptide and patent ductus arteriosus in preterm infants. Arch Dis Child 1987;62:1165-7.

22 Andersson S, Tikkanen I, Pesonen E, Wallgren EI, Fyhrquist F. Atrial natriuretic peptide and atrial pressures in newborns with transposition of natriuretic peptide and atrial pressures in newborns with

23 Kikuchi K, Nishioka K, Ueda T, et al. Relationship between plasma atrial natriuretic peptide concentration and hemodynamic measurements in children with congenital heart disease. F Pediatr 1987;111:335-42.

24 Davis AL, Godestein DS, Salcedo JR, Kuehl K, Pollack MM. Atrial natriuretic peptide: the relationship with volume overload, atrial tachycardia and critical illness. Crit Card Med 1987;15:417.

25 Rascher W, Tullassay T, Lang RE. ANP in plasma of volume-overloaded children with chronic renal failure. Lancet 1985;ii:303-5.

26 Ito Y, Kinoshita S, Kato H, Marumo F, Ando K. Plasma concentrations of atrial natriuretic peptide in children with persistent hypertension. Acto Paediatrica Faponica 1989;31:12-6.

27 van Hooft IMS, Grobbee DE, Hofman A, Schiffers P, de Pont JJH. Atria natriuretic factor and sodium intake in offspring of hypertensive and normotensive parents. N Engl $\mathcal{F}$ Med 1989;320:867.

28 Tunny TJ, Gordon RD. Plasma atrial natriuretic peptide in primary aldosteronism (before and after treatment) and in Bartter's and Gordon's syndromes. Lancet 1986;i:272-3. 